\title{
A CASE OF LEFT SIDED AMYAND'S HERNIA
}

S. Robindro Singh, Ch. Deepak Singh, Kh. Sunitarani Devi, K. Upendra Singh

1. Assistant Professor. Department of Surgery, Jawaharlal Institute of Medical Sciences, Porompat, Imphal.

2. Assistant Professor. Department of Surgery, Jawaharlal Institute of Medical Sciences, Porompat, Imphal.

3. Tutor. Department of Pathology, Jawaharlal Institute of Medical Sciences, Porompat, Imphal.

4. Assistant Professor. Department of Anaesthesia, Jawaharlal Institute of Medical Sciences, Porompat, Imphal.

\section{CORRESPONDING AUTHOR:}

Dr. S. Robindro Singh,

Singjamei Sougrakpam Leikai,

Imphal - 795008, Manipur.

E-mail: srobindro@yahoo.co.in

Ph: 00919402881986

ABSTRACT: A nine months old male baby presented with swelling in left groin. It turns out to be a rare presentation of Amyand's hernia, where the appendix was found within the left hernial sac during surgery for an obstructed inguinal hernia. Herniotomy and appendectomy was carried out since the appendix was inflamed.

INTRODUCTION: A vermiform appendix in an inguinal hernia sac, with or without appendicitis, is called Amyand's Hernia. Claudius Amyand (1660-1740), a French surgeon working at St.George's and Westminster hospitals in London, performed the first successful appendicectomy in 1735, on an 11year-old boy who presented with an inflamed, perforated appendix in his inguinal sac. Since then, the presence of the appendix within an inguinal hernia has been referred to as "Amyand's hernia", and still remains a rare occurrence. The case was published in the Philosophical Transactions of the Royal Society of London.

We present such a case of Amyand's hernia discovered at surgery for a left-sided obstructed inguinal hernia in a nine month old baby. Whether or not an appendectomy should be performed at the same times as the hernia repair is debatable. The aim of this study is to present the experience of our Institute surgical department with Amyand's hernia along with a review of the literature on this subject.

CASE REPORT: A male baby of nine months was admitted in our institute on $19^{\text {th }}$ May 2012 for swelling in the left groin from one day. Mother of the baby noticed the swelling which was gradual onset and progressive, more prominent on crying. There was no history of vomiting or abdominal distension. Past history reveals that patient had swelling on the same site since birth but it used to disappear on its own.

On examination baby is well nourished and looks to be irritated, crying most of the time. Vital signs are stable. Inspection reveals a globular shaped swelling of about $5 \times 3 \mathrm{cms}$ extending from left pubic tubercle to scrotum. Expands on crying. Palpation reveals elastic consistency and non reducible. Resonant note appreciated on percussion and peristaltic sound heard on auscultation. We prepared for surgery as diagnosed as irreducible left sided inguinal hernia. After administration of general anaesthesia, an incision was made in the skin crease of the left inguinal region, just above the superficial ring. After opening up the layers, hernial sac identified and opened, appendix and the caecum were found to be lying within, with minimal adhesions to 
the sac. Herniotomy and appendectomy carried out. Patient had an uneventful postoperative stay. A contrast study was done to rule out the possibility of situs inversus or malrotation of the gut, keeping in mind the unusual site of the appendix, but it was normal.

DISCUSSION: Acute appendicitis within an inguinal hernia accounts for $0.1 \%$ of all cases. Inflammation of the appendix is attributed to external compression of the appendix at the neck of the hernia. Amyand's hernia remains relatively unknown despite having been first reported nearly 170 years ago.

Most of the cases occur on the right side, probably as a consequence of the normal anatomical position of the appendix, and also because right sided inguinal hernias are more common than left- sided hernias. Left side Amyand's hernia is rare and may be associated with situs inversus, intestinal malrotation or a mobile caecum. Since we have rule out the first two conditions by contrast study, ours is due to mobile caecum.

Amyand's hernia is rarely diagnosed preoperatively and requires awareness of the disease process by the clinician in combination with the physical findings of a tender hernia without radiological or clinical evidence of obstruction.

Pre-operative computed tomography of the abdomen may be helpful in reaching the correct diagnosis.

The surgical options for tackling the appendix in an Amyand's hernia depend on the mode of presentation.

CONCLUSION: A hernia surgeon may encounter unexpected intraoperative findings, such as an Amyand's hernia. The decision as to whether one should perform a simultaneous appendectomy and hernia repair is multifactorial. It is important to be aware of all clinical settings and an appropriate and individualized approach should be applied.

\section{REFERENCES:}

1. Amyand C: of an inguinal rupture, with a pin in the appendix caeci, incrusted with stone; and some observations on wounds in the guts.philos Trans R Soc London 1736, 39:329336.

2. Carey L.C: Appendicitis occurring in hernias: a report of 10 cases. Surgery,1967,61:236.

3. Luch JS Halpern D, Katz DS Amyand's hernia: prospective CT diagnosis.J Comput Asssist Tomogr 2000;24:884-6.

4. Weber R.V., Hunt Z.C., Kral J.G.: Amyand's hernia: Etiologic and therapeutic implications of two complications. Surg Rounds, 1999,22:552-556.

5. Bakshi GD, Bhandarwar AH, Govila AA. Acute appendicits in left scrotum. Indian J Gastroenterol 2004; 23:195.

6. Franko J, Raftopoulos I, Sulkowski R. A rare variation of Amyand's hernia. Am J Gastroenterol 2002;97:2684-5. 


\section{CASE REPORT}

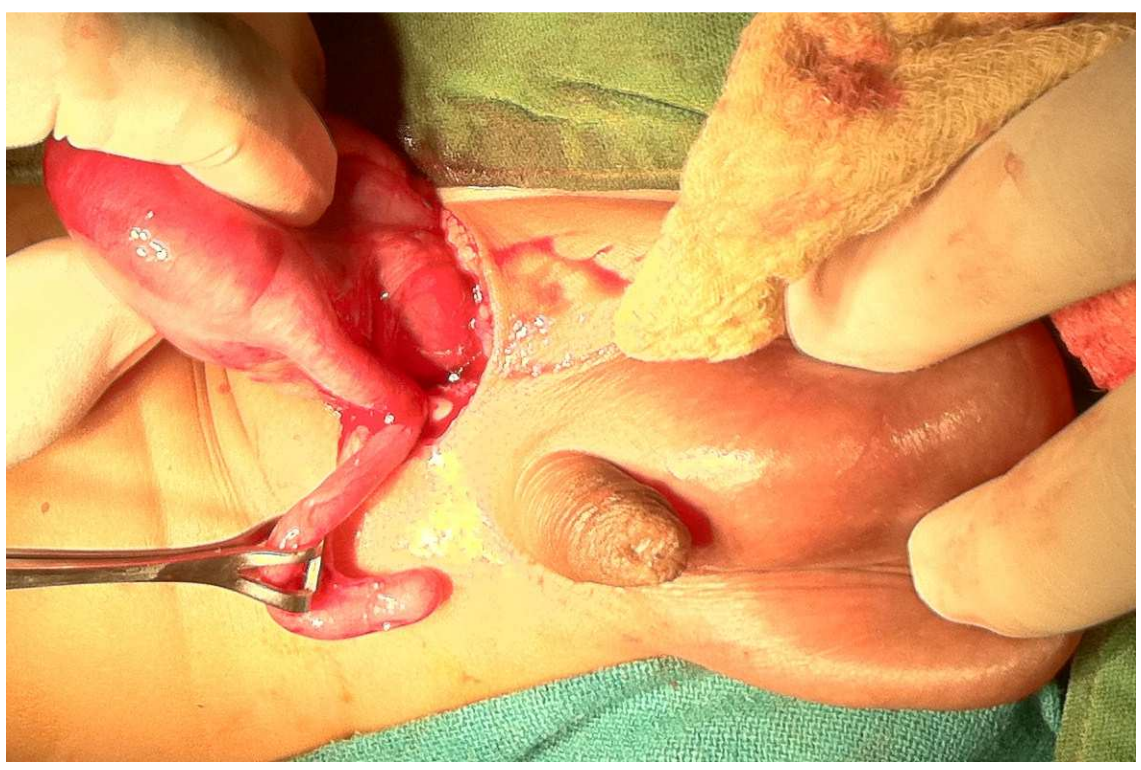

Appendix with Caecum through left inguinal hernia 